\title{
White-capped albatrosses alter fine-scale foraging behavior patterns when associated with fishing vessels
}

\author{
Leigh G. Torres ${ }^{1, *}$, David R. Thompson ${ }^{1}$, Stuart Bearhop ${ }^{2}$, Stephen Votier ${ }^{3}$, \\ Graeme A. Taylor ${ }^{4}$, Paul M. Sagar ${ }^{5}$, Bruce C. Robertson ${ }^{6}$ \\ ${ }^{1}$ National Institute of Water and Atmospheric Research Ltd., Kilbirnie, Wellington 6021, New Zealand \\ ${ }^{2}$ School of Biosciences, University of Exeter, Penryn, Cornwall TR10 9EZ, UK \\ ${ }^{3}$ Marine Biology and Ecology Research Centre, University of Plymouth, Plymouth PL4 8AA, UK \\ ${ }^{4}$ Department of Conservation, PO Box 10420, Wellington 6143, New Zealand \\ ${ }^{5}$ National Institute of Water and Atmospheric Research Ltd., Riccarton, Christchurch 8011, New Zealand \\ ${ }^{6}$ Department of Zoology, University of Otago, Dunedin 9016, New Zealand
}

\begin{abstract}
Incidental bycatch of seabirds in commercial fishing activities is known to cause declines in seabird populations. However, the full impacts on the ecology of seabirds, including effects on seabird distribution and behavior, through the association with fisheries are not fully understood. We developed a novel method to integrate fine-scale GPS tracking data from the foraging trips of 25 white-capped albatross Thalassarche steadi within sub-Antarctic New Zealand with fishing effort distribution data to (1) quantify fine-scale overlap between individual albatrosses and individual vessels and (2) characterize behavioral changes in albatrosses when they are associated with fishing vessels. Overlap between vessels and albatrosses occurred in $68 \%$ of tracks. However, albatrosses demonstrated high variability in foraging trip destinations and association rates with fishing activity, both between and within individuals. Eight tracks never overlapped a fishing vessel. Of the 17 tracks that did overlap, a range of 2 to $73 \%$ of foraging effort on each trip occurred while overlapping a fishing vessel. Albatross foraging behavior was characterized by a significantly slower and straighter path when overlapping vessels. This study highlights the utility of GPS tags to examine the fine-scale distribution of seabirds in relation to fishing activity, revealing how effects of fisheries on marine megafauna may extend beyond mortality and injury as well as population numbers. However, results are currently constrained, not only by limited tracking data sets, but also by the quality (spatio-temporal resolution) and availability of fishing effort data. Critical conservation issues related to the effects of fisheries on threatened marine megafauna cannot be fully addressed without comparative data sets with resolution equal to GPS tags.
\end{abstract}

KEY WORDS: Fisheries interaction $\cdot$ Foraging behavior $\cdot$ GPS tagging $\cdot$ Seabirds $\cdot$ Spatio-temporal scale $\cdot$ Telemetry $\cdot$ New Zealand $\cdot$ Squid trawl fishery

Resale or republication not permitted without written consent of the publisher

\section{INTRODUCTION}

Incidental bycatch of long-lived marine vertebrates by commercial fisheries is a global threat to marine ecosystems and biodiversity that occurs at fine spatial and temporal scales. Mortality rates of many marine megafauna species, including albatrosses, that interact with fishing activities are unsustainable, and could lead to declining populations (Lewison \& Crowder 2003, Sullivan et al. 2006) and associated ecological consequences (Lewison et al. 2004, Heithaus et al. 2008). Conservation of marine megafauna species prone to high bycatch rates requires an understanding of each population's association rates with fishing 
activities and the ecological effects of interactions. Our study integrates fine-scale data on the distribution of both individual bird movements and individual fishing vessels to elucidate how foraging patterns of whitecapped albatrosses Thalassarche steadi are modified due to the presence of fishing activities. Additionally, overlap rates between individual birds and individual fishing vessels are quantified. Our novel data, methods and results can lead to improved conservation strategies based on more precise estimates of population risks and ecological impacts.

Previously, overlap between fishing activity and seabird distribution has been documented on a relatively coarse scale (Prince et al. 1998, BirdLife International 2004, Phillips et al. 2006), identifying broad 'hotspots' of interaction. While this approach identifies areas of concern that necessitate mitigation measures, it tells us nothing of the way individuals respond to fishing vessels. Understanding such variation in response is important since individual strategies can have population-level consequences (Sutherland 1996). Recent advances in miniaturized bio-logging devices have enabled the detailed study of individual distribution patterns of birds at sea and, when combined with fisheries data, provide a powerful tool to better understand individual variation relative to fishing effort.

Trawlers can potentially provide an abundant resource of food for seabirds, from either processing waste or target catch, and therefore their activities frequently attract large numbers of seabirds (Bartle 1991, Weimerskirch et al. 2000). Albatross mortality during trawl interactions occurs as a result of entanglement in the nets and collision with trawl warps, the cables extending from the back of a trawl vessel that pull the nets. Trawl activities account for $75 \%$ of the estimated global annual bycatch of white-capped albatrosses (Baker et al. 2007). Furthermore, the white-capped albatross is the second most commonly killed seabird species in New Zealand fisheries, with approximately $81 \%$ of observed mortalities occurring in the New Zealand squid trawl fishery (Conservation Services Programme 2008). This fishery employs midwater or bottom trawls to target arrow squid Nototodarus spp., a common prey item of white-capped albatrosses (Cherel \& Klages 1998, BirdLife International 2008). The white-capped albatross is endemic to New Zealand and listed as near-threatened by the International Union for the Conservation of Nature (IUCN) Birdlife International (BirdLife International 2008). Given the evidence for high rates of incidental mortality of whitecapped albatrosses associated with commercial fisheries in New Zealand and overseas, there is an urgent need to better understand their population dynamics and ecological impacts due to fishing activities.
In the present study, we employed high-resolution GPS tags to record the at-sea distribution of whitecapped albatrosses and overlaid these tracks in space and time with fishing vessel location and activity data. Through this comparison, we (1) quantify and describe the fine-scale overlap between individual whitecapped albatrosses and commercial fishing activity and (2) characterize changes in white-capped albatross foraging behavior patterns when and when not associating with fishing vessels. To the best of our knowledge this is the first examination of individual seabird interactions with individual fishing boats, which allows association rates to be quantified and ecological impacts on behavior patterns to be assessed.

\section{MATERIALS AND METHODS}

The white-capped albatross Thalassarche steadi breeds primarily at the Auckland Islands archipelago in the New Zealand sub-Antarctic (Fig. 1) and has an estimated population of 75000 breeding pairs (Gales 1998). Our study was conducted in February 2006, during the brood-guard stage, when white-capped albatrosses make relatively short foraging trips and remain in Australasian waters. It is during this time period that they appear to be most prone to fisheries bycatch in New Zealand. A third of all white-capped albatrosses that were returned for autopsy between 1996 and 2002 had been killed during February (Robertson et al. 2004). Moreover, $86 \%$ of the fishing effort by the New Zealand squid trawl fishery occurs between January and March, predominantly around New Zealand's sub-Antarctic islands, close to whitecapped albatross breeding sites (Bartle 1991, Baker et al. 2007).

Field methods. In February 2006, we deployed 20 GPS data-logging tags ('GPSlog' tags, Earth \& Ocean Technologies) on chick-guarding adult whitecapped albatrosses at South West Cape $\left(50.83^{\circ} \mathrm{S}\right.$, $165.90^{\circ} \mathrm{E}$ ), Auckland Islands (Fig. 1). We captured the birds by hand and deployed each tag to the mantle feathers between the wings by means of waterproof Tesa ${ }^{\circledR}$ tape. Each deployment took approximately 5 min to complete and all birds were successfully returned to their nest pedestal where they continued to brood their chick. GPS tags weighed approximately $65 \mathrm{~g}$, or $<1.5 \%$ of the bird's body mass, and were programmed to acquire a GPS fix every 3 min. Ninety percent of fixes were estimated to be within $19 \mathrm{~m}$ of the true location (Earth \& Ocean Technologies unpubl. data). We successfully retrieved GPS devices from 19 birds; the nest of the remaining bird was destroyed by feral pig Sus scrofa activity and we did not observe the bird at the colony for the remainder of our visit. During 

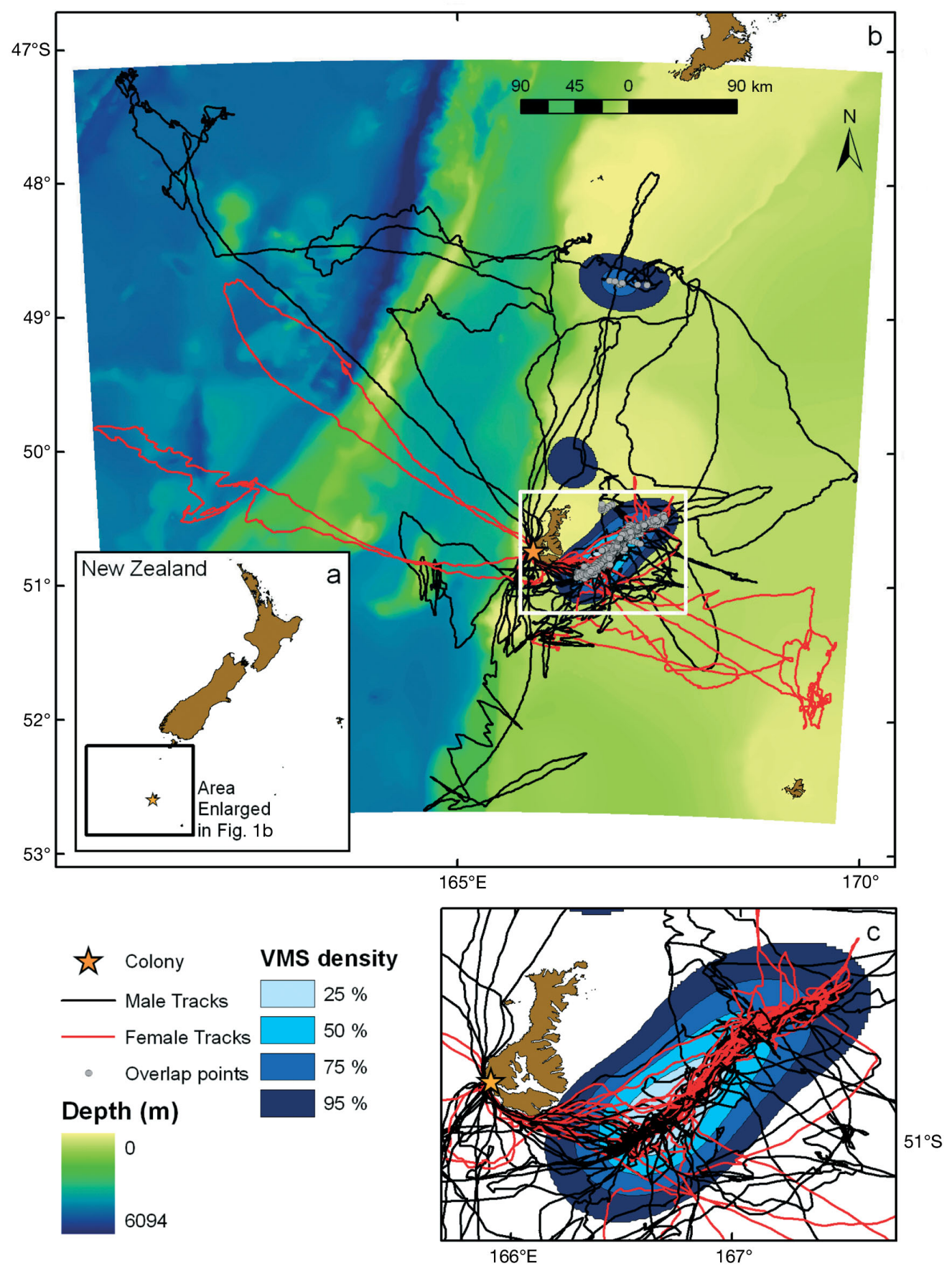

Fig. 1. Thalassarche steadi. (a) Location of the Auckland Islands, New Zealand. (b) Location of South West Cape colony with all 25 white-capped albatross GPS tracks depicted and color-coded by sex. Tracks are overlaid on regional bathymetry and utilization distribution kernels of all vessel monitoring system (VMS) points from non-steaming squid trawlers during the same temporal period as when white-capped albatrosses were tagged and tracked from the Auckland Islands (smoothing factor $=11.79 \mathrm{~km}, 150 \mathrm{~m}$ cell size). Grey dots represent GPS points identified as overlapping a fishing vessel. White box demarcates the Auckland Islands shelf region where high white-capped albatross activity occurred. (c) Enlargement of white box in (b) to illustrate high density of GPS tracks and vessels over Auckland Islands shelf

recapture of each bird for GPS device retrieval, we obtained approximately $0.5 \mathrm{ml}$ of blood to determine the bird's gender (molecular sexing methods used are found in Appendix 1).
Albatross behavior characteristics. When an individual animal begins to forage or search more intensively for food, it usually reduces its speed and uses a more sinuous path (Benhamou \& Bovet 1989). There- 
fore, to characterize changes in foraging behavior patterns of albatross GPS tracks relative to association with fishing vessels, we derived behavior data for each point along all tracks: speed, straightness and residence. Speed for each point was calculated as the speed of travel between the point of detection and the previous point $\left(\mathrm{km} \mathrm{h}^{-1}\right)$. An index of path straightness was determined for each point over a 30 min window ( \pm 5 GPS points) and was measured as a ratio of the straight line distance between 2 points and the distance travelled (Weimerskirch et al. 2002). Straightness index values ranged from 0 to 1 . High values indicate increased path straightness and low values indicate greater track sinuosity. Residence is a measure of time spent in an area and is calculated by summing the various movement portions within virtual circles of a constant radius centered at successive locations along an individual's path (Barraquand \& Benhamou 2008). Residence time is similar to the commonly used measure of animal movement, first passage time (FPT) (Fauchald \& Tveraa 2003), but is more objective because it does not rely on interpretation of plots but rather measurements of time spent in each segment and is able to apply a value to each point along a track. By means of the Pascal code provided by Barraquand \& Benhamou (2008), we calculated residence values for each point along every track using spatial segments of $200 \mathrm{~m}$ and a search radius of $2 \mathrm{~km}$, with a threshold of 5 GPS points for path segments outside this search radius. These parameters were chosen to provide an accurate and reliable fine-scale representation of changes in behavior while also consistent with the resolution of the GPS track data and the behavioral responses of albatrosses. A radius of $2 \mathrm{~km}$ was applied because it is a realistic estimate of an individual albatross' likely range of habitat perception at any one location (Nevitt 2008).

For all data analysis, we excluded all points within $5 \mathrm{~km}$ of the colony and all 'drift' points. Drift points describe points when the bird was probably resting on the water. We defined drift points as points with a mean value over a $1 \mathrm{~h}$ window $( \pm 15$ points) of path straightness $\geq 0.9$ (straight), speed $\leq 4.25 \mathrm{~km} \mathrm{~h}^{-1}$ (slow) and distance between points $\leq 0.15 \mathrm{~km}$ (small). While these cut-off values were subjective, they were selected based on trial and error and meaningfully classified points that could be identified as drift points based on a visual inspection of the data. It was important to identify drift points and subsequently remove them from the data set for analyses because drift points had elevated residence values, swamping other points with otherwise high residence values that indicated foraging. Therefore, with drift points removed from the data set we reduced the chances of mistakenly characterizing resting points as foraging points.
Comparisons of behavioral patterns relative to overlap with fishing vessels were limited to GPS points from tracks of birds considered to be foraging. We focused our analysis on foraging points to investigate how albatross foraging behavior differs when individuals are associated with fishing vessels compared with when not associated. Foraging points were identified as those points within each track with residence values in the top quartile, calculated with drift points removed. Path straightness was not used as an index of foraging behavior because it is confounded by the fact that birds travel in a relatively straight line when foraging behind trawlers, unlike 'naturally' foraging birds that turn frequently while searching for prey (see Fig. 6). All data analyses were conducted in Matlab ${ }^{\circledR}$ v. 7.6, R2008a (The MathWorks).

Quantifying association with fishing vessels. We focused on the relationship between the commercial squid trawl fishery and the distribution of white-capped albatrosses because this was the only fishing activity that occurred during the same temporal period and spatial extent as did the bird tracks. Fine-scale fishing effort data were deduced with 2 data sets provided by the New Zealand Ministry of Fisheries. Every New Zealand fishing vessel exceeding $28 \mathrm{~m}$ in overall length and all foreign fishing vessels in New Zealand's Exclusive Economic Zone are required to carry a GPS transponder. This vessel monitoring system (VMS) accurately records a vessel's location in time and space, but data points are typically only acquired every 1 to $2 \mathrm{~h}$ and, besides speed, no vessel activity data (e.g. fishing, setting or hauling a net) are recorded. In addition to this VMS data set, we used a catch effort database (Ministry of Fisheries 2006) that provided locations and times for every trawl event (sets and hauls). Although this catch effort data set provides vessel activity data, the accuracy of event locations, in time and space, is low relative to albatross GPS tracks and VMS data. Locations of sets and hauls were recorded to the nearest minute and time stamps were frequently rounded to 5 min increments, producing potential spatial error of up to $2 \mathrm{~km}$ and unknown temporal error. We integrated the VMS and catch effort data sets to identify overlap and interaction points between all recorded albatross tracks and fishing effort.

First, we used the VMS data set to identify points along the albatross tracks that overlapped spatially and temporally with a fishing vessel. VMS points were highly accurate, yet we did not know the vessel's exact location in between consecutive points. Therefore, we generated circular spatial buffers of variable radius sizes around interpolated points placed at 3 min intervals along a straight-line path between consecutive VMS points (a full description of methods used to identify overlap between albatross GPS points and fishing 
vessels can be found in Appendix 2). Intervals of 3 min each were used because this was the same sampling rate as used in the albatross GPS tags. The radius size of each circular spatial buffer was calculated based on the fact that the location of the vessel at the 2 end (VMS) points was certain, but the position of the vessel becomes more uncertain with increasing distance from these end (VMS) points. Therefore, the size of the circular buffers around each 3 min point is based on its distance from the closest end point, with the midpoint (MP) having the largest buffer because this point has the greatest uncertainty of the vessel's location (Fig. 2).

Radius buffer sizes were calculated as follows. For every pair of consecutive VMS points, we calculated the 'excess distance' (eD) between those points, defined as the extra distance, in addition to the actual distance between points, that the vessel could have travelled if it maintained a constant speed and travelled in a straight line between the 2 VMS points. The eD was calculated as the difference between the potential distance the vessel could have travelled (average vessel speed $\times$ time between start and end points) and the actual distance between the start and end locations. Theoretically, the farthest the vessel could have travelled off the straight-line track from the initial VMS point and still make it to the end VMS point in the same amount of time is eD/2. This maximum distance of the tangent line $(c)$ from the initial VMS point occurs at the MP of the track $\left(c_{\mathrm{MP}}=\mathrm{eD} / 2+\right.$ $b$, where $b$ is the distance to the MP from the end points) because this is the point of greatest uncertainty of the vessel's location in between the 2 known VMS points. A right-angle triangle was created at the MP with the lengths of $c$ and $b$. Based on the Pythagorean theorem $\left(a^{2}=b^{2}+c^{2}\right)$, the value of $c$, and the distance to the MP from the end points $(b)$, we calculated the radius size (a) for the spatial buffer at the MP as: $a=$ $\sqrt{\left(c^{2}-b^{2}\right)}$. The radius sizes $\left(r^{\mathrm{i}}\right)$ for all other 3 min points along the straight-line vessel track were calculated as an incremental proportional value of $a$, increasing in size with increasing distance from the closest VMS point. Finally, albatross track GPS points were overlaid on the spatial buffers to identify the overlap state (overlapping or non-overlapping) of each point. Those points that fell within the radius buffers and within a $\pm 3 \mathrm{~min}$ temporal window of the VMS point or interpolated 3 min intervals along the vessel tracks were identified as overlapping. Code was written in Matlab ${ }^{\circledR}$ to iteratively perform these spatial and temporal comparisons between every albatross and fishing vessel track.

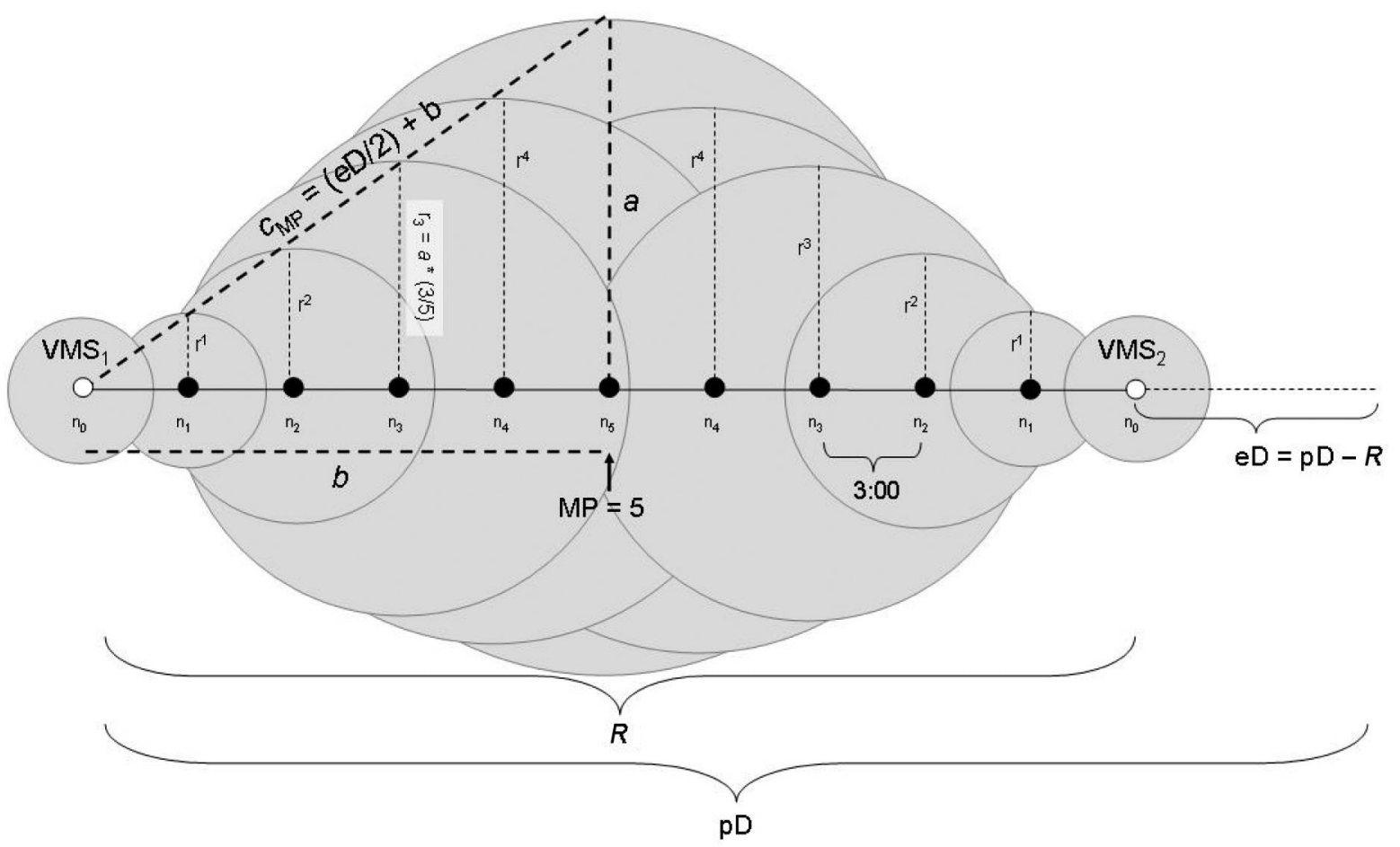

Fig. 2. Schematic illustration of how radii $\left(r^{\mathrm{i}}\right)$ for spatial buffers were calculated for a vessel track between 2 consecutive vessel monitoring system (VMS) points $\left(\mathrm{VMS}_{1}\right.$ and $\left.\mathrm{VMS}_{2}\right)$, represented by white circles. Black circles are generated points at 3 min intervals $\left(\mathrm{n}_{\mathrm{i}}\right)$. The radius of the midpoint (MP) spatial buffer, $a$, is calculated based on the Pythagorean theorem; i.e. $a=\sqrt{\left(c^{2}-b^{2}\right)}$ and the values of $c_{\mathrm{MP}}(1 / 2 \mathrm{eD}+b)$ and $b(\mathrm{MP} \times \mathrm{dR})$. Radii for other spatial buffers at 3 min interval points $\left(\mathrm{n}_{\mathrm{i}}\right)$ calculated as a proportional value of $a$ based on distance from the closest VMS point (see 'Materials and methods: Quantifying association with fishing vessels' and Appendix 2 for explanation) 
Next, we cross-referenced all albatross GPS points identified as overlap with the catch effort data set to identify 'interaction' points with trawlers. We focused on haul and set locations to identify potential interaction points because this was the data set available to us and where relatively high mortality rates of whitecapped albatrosses are likely to occur (Bartle 1991). For every overlap point, we determined whether the associated vessel performed either a net set between the recorded bird time and $30 \mathrm{~min}$ before, or a haul between the recorded bird time and 30 min after. On average, hauls and net sets take about $20 \mathrm{~min}$ to complete (Baird 2008), and set times are not recorded until the net reaches its fishing depth and haul times are recorded when the net leaves its effort depth. However, to an albatross, a set begins when the net first hits the water and a haul does not end until the net leaves the water (Bartle 1991). Therefore, the time window of interaction for the set period was determined to be the recorded set time minus $30 \mathrm{~min}$, and for the haul period was determined to be the recorded haul time plus 30 min. Finally, only points designated as foraging (residence value in the top quartile of the track) were considered interaction points; otherwise, the bird was considered to be travelling through the area and not actually interacting with the vessel.

Data analysis. ANOVA tests were conducted with all foraging points to identify the effect of overlap state (non-overlap or overlap) on path straightness and speed. Initially, the entire data set was analyzed without accounting for variation caused by individual albatross. Next, we considered each individual albatross as the sampling unit and conducted ANOVAs with individual nested within overlap state.

Additionally, a linear regression was conducted to assess the relationship between total trip length $(\mathrm{km})$ and the percentage of foraging points identified as overlapping along each track. Two-sample $t$-tests were used to detect the difference in track characteristics (duration, distance, percentage of foraging points identified as overlapping) between track destinations and gender. A kernel density plot of all non-steaming (vessel not in transit) VMS points (calculated accord- ing to Rodgers et al. 2007) obtained during the same temporal period as the albatross tracks was created to visualize the distribution of fishing effort.

\section{RESULTS}

\section{Characterization of foraging behavior}

The GPS tags that were successfully retrieved from 19 white-capped albatrosses Thalassarche steadi recorded 25 foraging trips between 3 and 11 February 2006. Six birds completed 2 trips while tagged. Sexing methods determined that 7 female and 12 male albatrosses were tagged. The birds travelled to diverse destinations and used a variety of habitats (Fig. 1b). However, a concentration of tracks is evident in one area over the Auckland Islands (AI) shelf, at the $250 \mathrm{~m}$ isobath (white box in Fig. 1b), and 13 out of the 25 foraging trips did not extend beyond this area. Of the 12 other tracks that dispersed beyond this area, 7 tracks also occurred over the AI shelf during a portion of the foraging trip. Only 5 of the 25 tracks did not travel through the AI shelf at any time. Density kernels of VMS points from nonsteaming (transit points removed) squid trawlers during the same temporal period as the tracking data illustrate how trawlers and a majority of albatross tracks targeted the same area over the AI shelf (Fig. 1c).

Mean albatross foraging trip duration was $42.92 \mathrm{~h}$ and mean trip distance was $977.35 \mathrm{~km}$ (Table 1). Those 13 tracks that occurred over the AI shelf were significantly shorter in distance $(p=0.006)$, but not in duration $(p=0.357)$, than the 12 non-AI shelf tracks. A significant difference was detected $(p=0.01)$ in the percent of foraging points identified as overlapping a fishing vessel between trip destinations (AI or non-AI, Table 1). A linear regression between trip length $(\mathrm{km})$ and percentage of overlapping foraging points along each track revealed an $\mathrm{r}^{2}$ value of 0.07 and a $\mathrm{p}$-value of 0.204 . Although these statistics indicate a non-significant relationship, a scatterplot of data points indicates a trend of decreased trip length with increased overlap rate (Fig. 3).

Table 1. Thalassarche steadi. Comparison of albatross GPS track characteristics by destination and overlap state. AI: Auckland Island shelf

\begin{tabular}{|lcccccrc|}
\hline & $\mathrm{n}$ & $\begin{array}{c}\text { No. of } \\
\text { foraging } \\
\text { points }\end{array}$ & $\begin{array}{c}\text { No. of } \\
\text { overlapping } \\
\text { foraging } \\
\text { points }\end{array}$ & $\begin{array}{c}\text { Mean trip } \\
\text { duration } \\
\text { (decimal } \\
\text { time) (SE) }\end{array}$ & $\begin{array}{c}\text { Mean trip } \\
\text { distance } \\
(\mathrm{km})\end{array}$ & $\begin{array}{c}\text { Mean of } \\
\text { overlapping } \\
\text { foraging points } \\
(\%)(\mathrm{SE})\end{array}$ & $\begin{array}{c}\text { Minimum and } \\
\text { maximum of } \\
\text { overlapping foraging } \\
\text { points (\%) }\end{array}$ \\
\hline All tracks & 25 & 4424 & 799 & $42.92(3.47)$ & $977.35(101.02)$ & $18.11(4.21)$ & $0,72.8$ \\
AI tracks & 13 & 2073 & 576 & $39.78(3.82)$ & $724.08(76.66)$ & $28.06(6.15)$ & $0,72.8$ \\
Non-AI tracks & 12 & 2351 & 223 & $46.32(5.95)$ & $1251.71(162.12)$ & $8.15(3.36)$ & $0,30.1$ \\
\hline
\end{tabular}


Significant differences were found between the overlap state of all foraging points in path straightness $(F=40.07, \mathrm{p}<0.001, \mathrm{df}=1)$ and speed $(F=23.17, \mathrm{p}<$ 0.001 , df $=1$ ). With individual bird nested within overlap state, path straightness and speed were still significantly different relative to overlap state of foraging points (Table 2). Plots of means and SE show that when foraging while overlapping a fishing vessel, albatrosses traveled in a straighter line (Fig. 4a) and more slowly (Fig. 4b) than when foraging while not overlapping a fishing vessel.

\section{Albatross-fishery relationships}

The radius buffering method of VMS tracks produced buffers with radius sizes ranging from $<100 \mathrm{~m}$ to $28 \mathrm{~km}$, yet $91 \%$ of all buffers had a radius less than $7 \mathrm{~km}$. Spatial buffers with radii larger than $7 \mathrm{~km}$ are due to long time gaps $(>2 \mathrm{~h}$ ) between consecutive VMS points. Additionally, $95 \%$ of all buffers that overlapped with an albatross GPS point in space and time had radii less than $7.5 \mathrm{~km}$. These results indicate that a relatively small scale of analysis was maintained to evaluate overlap between individual white-capped albatrosses and individual trawl vessels.

Based on the radius buffering method of VMS data, 17 out of 25 tracks (68\%) included foraging points that were identified as overlapping a trawler. Unsurprisingly, $99 \%$ of these overlap points occurred in the AI shelf region where most of the fishing activity occurred (Fig. 1b). The percentage of overlapping GPS points during the day $(13.1 \%)$ was nearly double the nighttime rate of overlap $(7.7 \%)$; however, there was high variation in diurnal overlap rates between tracks and individuals. On average, $22.1 \pm 1.72 \%$ (mean $\pm \mathrm{SD}$ ) of albatross foraging trips were identified as foraging

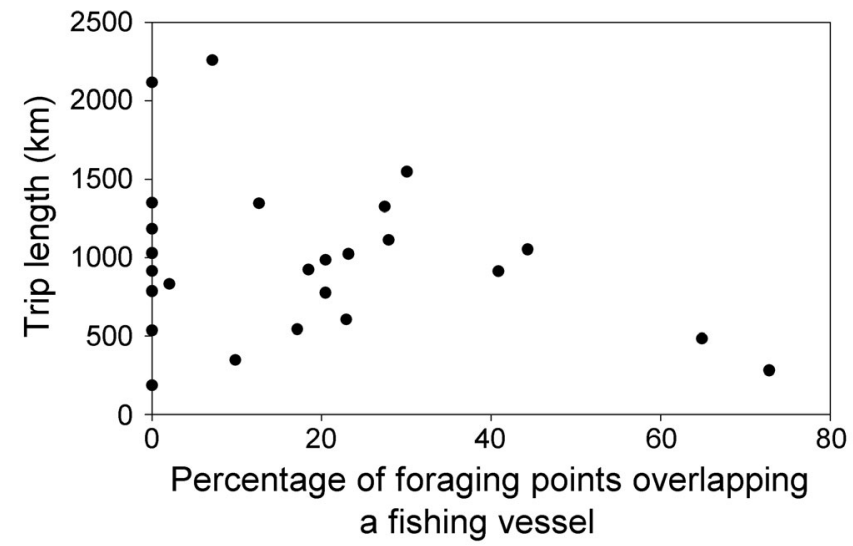

Fig. 3. Thalassarche steadi. Scatterplot of trip length $(\mathrm{km}) \mathrm{rel}-$ ative to percentage of foraging overlap points for each track (linear regression results: $\mathrm{r}^{2}=0.07, \mathrm{p}=0.204$ )
Table 2. Thalassarche steadi. ANOVA results using all foraging points to identify the effect of overlap state (overlap or non-overlap) on path straightness and speed, with individual bird nested within overlap state

\begin{tabular}{|c|c|c|c|c|}
\hline Source & SS & df & $F$ & $\mathrm{p}$ \\
\hline \multicolumn{5}{|l|}{ Path straightness } \\
\hline Overlap state & 0.479 & 1 & 7.54 & 0.0061 \\
\hline $\begin{array}{l}\text { Individual (nested } \\
\text { in overlap state) }\end{array}$ & 63.277 & 30 & 33.17 & 0 \\
\hline Error & 345.688 & 4423 & & \\
\hline \multicolumn{5}{|l|}{ Speed } \\
\hline Overlap state & 1032.1 & 1 & 10.08 & 0.0015 \\
\hline $\begin{array}{l}\text { Individual (nested } \\
\text { in overlap state) }\end{array}$ & 48320.4 & 30 & 15.73 & 0 \\
\hline Error & 449675.3 & 4392 & & \\
\hline
\end{tabular}

behavior (high residence values). Of all 4424 GPS points determined to be foraging points, $18.5 \%$ occurred while overlapping with a fishing vessel (Table 1). However, individual tracks had a variable amount of overlap with vessels, and this variability did not differ by gender $(t=0.175, \mathrm{p}=0.863$, df $=23)$. Eight tracks never overlapped with a fishing vessel while foraging; however, albatrosses in 4 tracks spent over $40 \%$ of their foraging effort while overlapping a vessel (Table 3). Remarkably, analysis of one albatross track revealed that three-quarters $(73 \%)$ of this bird's foraging effort was in association with a fishing vessel. The 6 birds that completed 2 foraging trips while tagged were not consistent in their destination or in their rate of overlap with fishing vessels (Table 3). This result indicates that individuals vary their foraging patterns between trips. On average, tracks overlapped with 10 $(\mathrm{SE}=1.3$, maximum $=17)$ different trawlers per trip.

Interaction events between GPS points designated as foraging and sets and hauls conducted by trawlers were identified at $14.4 \%$ of overlapping points ( $\mathrm{n}=$ 115). Out of 25 tracks, 11 included foraging points identified as interaction events, and of the 19 tracked birds 10 interacted with a trawler at some point during a foraging trip. More interaction points occurred during the day $(\mathrm{n}=87$ ) than at night $(\mathrm{n}=28)$, and more interaction points occurred with sets $(n=90)$ than hauls $(\mathrm{n}=46)$. Owing to the close proximity at which trawlers operate, and the relatively low spatial and temporal resolution of the catch effort data, individual GPS track points were occasionally $(n=34)$ identified as interacting with more than one vessel at one point. Four fishing events (set or haul) were identified as interacting with multiple tagged albatrosses during this study. Foraging points identified as interaction events had low path straightness values (mean $=0.644$ ) and slow speed (mean $=3.45 \mathrm{~km} \mathrm{~h}^{-1}$ ). During the period in which white-capped albatrosses were 

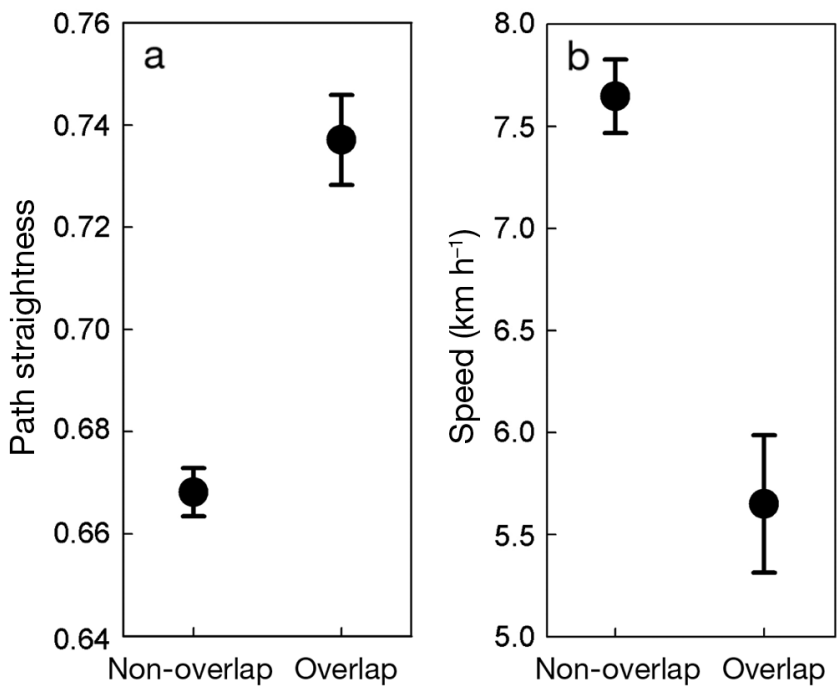

Fig. 4. Thalassarche steadi. Mean values of (a) path straightness and (b) speed with SE values of foraging points grouped by overlap state (overlap or non-overlap). Path straightness determined for each point over a 30 min window $( \pm 5$ GPS points) as the ratio of the straightline distance between 2 points and the distance travelled

Table 3. Thalassarche steadi. GPS track characteristics for each recorded foraging trip relative to overlap state with a fishing vessel and foraging effort. Foraging points defined by residence values in the top quartile (see 'Materials and methods'). Track number identifies individual tagged albatrosses; letters indicate the first (a) and second (b) trips for the 6 birds that completed 2 foraging trips while tagged. Data are sorted by the last column (\% of overlapping foraging points)

\begin{tabular}{|c|c|c|c|c|c|}
\hline Track & Gender & $\begin{array}{c}\text { Total GPS } \\
\text { points } \\
\text { along track }\end{array}$ & $\begin{array}{c}\text { \% of points } \\
\text { labeled } \\
\text { overlap }\end{array}$ & $\begin{array}{l}\% \text { of points } \\
\text { identified as } \\
\text { foraging }\end{array}$ & $\begin{array}{c}\% \text { of overlapping } \\
\text { foraging } \\
\text { points }\end{array}$ \\
\hline 30 & Male & 692 & 0.00 & 22.11 & 0.00 \\
\hline $33 a$ & Male & 220 & 0.00 & 19.09 & 0.00 \\
\hline $33 b$ & Male & 1490 & 0.00 & 24.63 & 0.00 \\
\hline $36 b$ & Male & 373 & 9.38 & 22.52 & 0.00 \\
\hline 38 & Female & 900 & 0.00 & 23.11 & 0.00 \\
\hline 42 & Female & 945 & 0.00 & 22.01 & 0.00 \\
\hline 45 & Male & 474 & 0.00 & 23.84 & 0.00 \\
\hline 46 & Female & 418 & 0.00 & 23.21 & 0.00 \\
\hline 41 & Female & 1128 & 14.54 & 21.63 & 2.05 \\
\hline $37 b$ & Male & 1303 & 3.30 & 23.71 & 7.12 \\
\hline $35 a$ & Female & 335 & 8.36 & 18.21 & 9.84 \\
\hline 47 & Male & 890 & 6.07 & 22.25 & 12.63 \\
\hline 32 & Male & 597 & 17.92 & 23.45 & 17.14 \\
\hline $40 a$ & Male & 915 & 14.43 & 21.31 & 18.46 \\
\hline 44 & Male & 800 & 21.88 & 22.00 & 20.45 \\
\hline $29 a$ & Male & 694 & 9.37 & 23.92 & 20.48 \\
\hline $36 a$ & Male & 613 & 6.69 & 23.49 & 22.92 \\
\hline $29 b$ & Male & 807 & 9.54 & 21.93 & 23.16 \\
\hline 43 & Female & 923 & 13.33 & 22.10 & 27.45 \\
\hline 10 & Male & 885 & 26.33 & 24.29 & 27.91 \\
\hline $40 \mathrm{~b}$ & Male & 1324 & 12.69 & 21.60 & 30.07 \\
\hline 48 & Male & 743 & 22.61 & 22.07 & 40.85 \\
\hline $35 b$ & Female & 1177 & 27.19 & 20.14 & 44.30 \\
\hline $37 a$ & Male & 509 & 22.99 & 21.81 & 64.86 \\
\hline 31 & Female & 686 & 37.90 & 18.22 & 72.80 \\
\hline
\end{tabular}

tracked, 30 fishing vessels performed 624 trawls, which equaled 1248 events (sets and hauls). Tagged birds interacted with $50 \%$ of these vessels and $10.9 \%$ of these events.

\section{DISCUSSION}

Our fine-scale examination of white-capped albatross foraging behavior patterns relative to commercial fishing activity revealed that birds move in straighter paths and at slower speeds when overlapping a squid trawler than when foraging naturally. This change in foraging behavior is probably because, at this scale of analysis, albatrosses that trail trawlers travel more slowly and in straighter paths mimicking the trawler's activities, as compared with 'natural' foraging behavior that involves greater speed changes and frequency of turns (Fig. 5). We believe that the bird is not in constant flight while overlapping a vessel. Rather, the albatross is probably sitting on the water paddling with its feet and flying short distances to maintain pace with the vessel and compete for position with other seabirds. We acknowledge that our methods to determine foraging points based on high residence values, essentially a measure of area restricted search (ARS), did not capture all foraging events. Previous studies have documented other albatross foraging strategies, such as 'directed flight' (Weimerskirch et al. 2007) and 'sit and wait' (Croxall \& Prince 1994), proving that ARS is just one foraging tactic for albatrosses. However, we believe that our methods successfully identified a majority of foraging points along each track where the individual searched for prey or was associated with a fishing vessel, enabling a successful behavioral comparison between overlap states. Our results indicate that white-capped albatrosses adjust their foraging behavior when associating with fishing vessels, suggesting that the ecological consequences of fishing activities on white-capped albatrosses, as well as all seabirds that interact with fishing gear, may extend beyond the direct effects of mortality and injury.

During $9 \mathrm{~d}$ of GPS tracking, $68 \%$ (13/19) of tagged birds overlapped with a commercial fishing vessel at some point during their foraging trip. Likewise, $68 \%(17 / 25)$ of foraging trips 
overlapped with a fishing vessel at some point. We can extrapolate this estimated rate of white-capped albatross overlap with fishing vessels during February using the population estimate of 75000 breeding pairs (Gales 1998). If approximately 75000 white-capped albatrosses are performing foraging trips at any one time, then over a $9 \mathrm{~d}$ period an estimated 51000 whitecapped albatrosses $(75000 \times 0.68)$ will overlap a fishing vessel during their foraging trip. This estimate does not take into account the amount of foraging time spent overlapping a fishing vessel, which based on our results, can range from 2 to $73 \%$ (Table 3 ). Although the robustness of the overlap estimate for this population could be improved with an increased sample size of tracks, the results are based on the best available data. This simple extrapolation reveals a large number of albatrosses from an endemic, threatened population potentially interacting with fishing activities and modifying their foraging behavior in association with the vessels. Also, during this same period of tracking between 3 and 11 February 2006, 7 white-capped albatrosses were caught and killed by vessels in the New Zealand squid trawl fishery (Thompson 2009). This is a minimum estimate of bycatch because observer effort is not standardized. Although this estimate of bycatch may appear relatively low when compared with a potential 51000 overlapping albatrosses, 7 fisheries-related mortalities of a protected albatross in $9 \mathrm{~d}$ is rather high.

The AI shelf is only $45 \mathrm{~km}$ from the colony, so a significant difference in distance travelled between AI and non-AI tracks is not surprising since those individuals that foraged elsewhere travelled farther to reach their foraging destinations. This result combined with
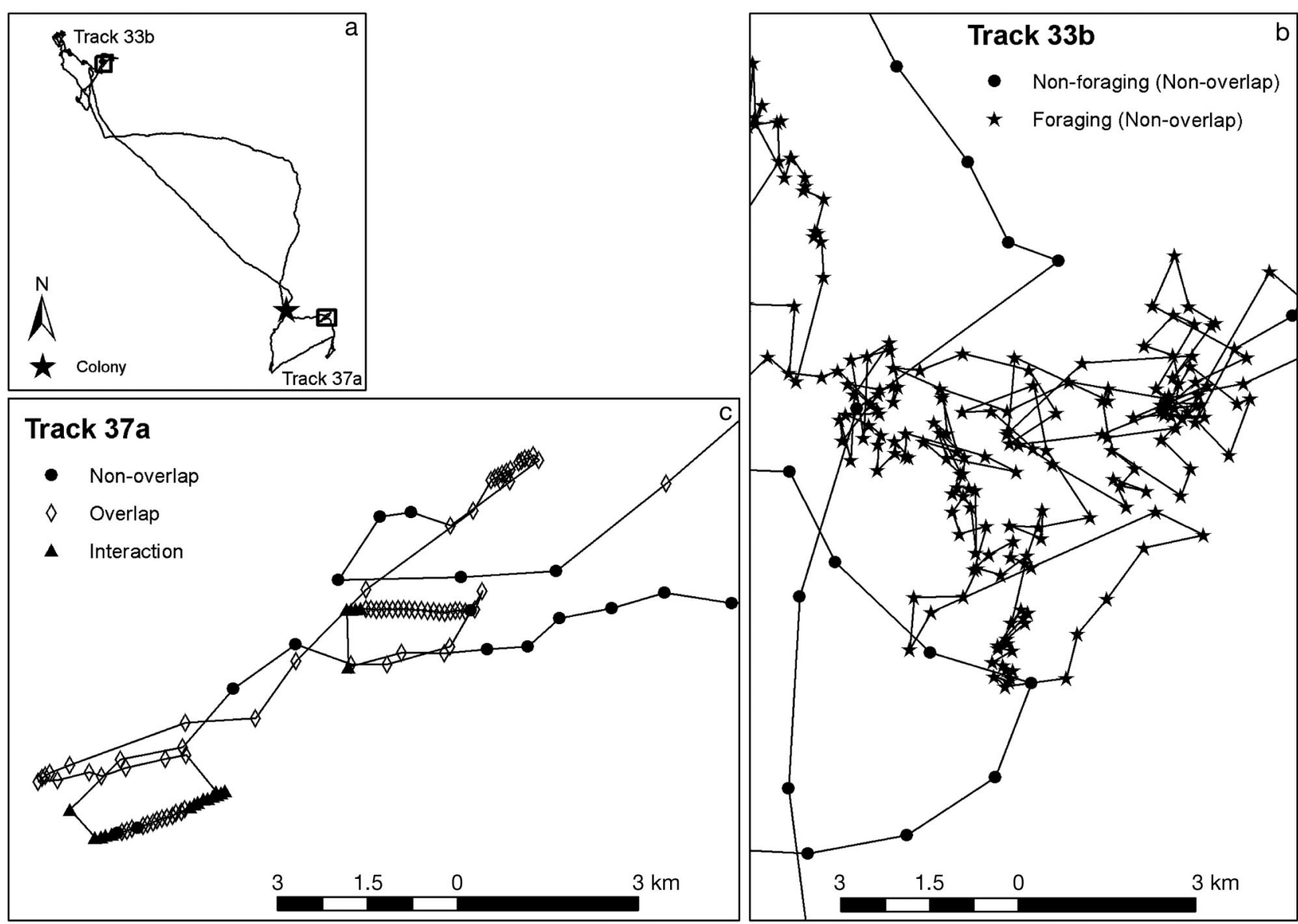

Fig. 5. Thalassarche steadi. Variation in albatross movement patterns by association with fishing vessels. (a) Overview of track destinations with black boxes demarcating area of each track enlarged. (b) Track 33b illustrates 'natural' foraging behavior, displaying frequent turns, in absence of fishing vessel association. Each GPS point is labeled by behavior state (foraging or nonforaging) based on residence values (see 'Materials and methods'). (c) Track 37a illustrates a track with a high overlap rate with fishing vessels over the Auckland Island (AI) shelf. Each GPS point is labeled by overlap and interaction state, which is designated based on methods with vessel monitorig system (VMS) and catch effort data sets (see 'Materials and methods'). Notice how the albatross flying track 37 a follows a pattern of flying in quickly, trailing a trawler slowly, flying away quickly, trailing another trawler slowly and so on. This was a common feature of tracks over the AI shelf 
the fact that there was no difference in trip duration indicates that those albatrosses that flew non-AI tracks may have spent more time in transit and less time foraging. AI tracks had significantly higher rates of overlap with fishing vessels while foraging, which is expected because fishing vessels were most dense in this area (Fig. 1c). These results correspond to the trend visually evident in Fig. 3 that indicates foraging trips may become shorter in distance with increased overlap rates when foraging, although this trend is not statistically significant. While this result may be confounded by the close proximity of fishing effort to the colony, it demonstrates the extent to which some albatrosses travel to forage independently of fishing activities.

Our analyses revealed a lack of consistency in foraging trip destination and overlap rates with fishing vessels, both between individuals and within separate foraging trips by the same bird (Table 3). Replicate tracks from individual birds are required to determine what drives variability in foraging habitat and how this may relate to variation in overlap rates with vessels. It is premature to speculate on the advantages or disadvantages for a white-capped albatross to associate with fishing vessels. First, we do not know the quality of food received from interactions with squid trawlers relative to natural foraging. Additionally, we do not know whether an albatross that is overlapping with a vessel is actually associating with the vessel; the bird and boat could be in same habitat for the same resource. Further research into these 2 areas, through nutritional analyses and more fine-scale vessel distribution data, will aid our ability to fully evaluate and understand the effects of fishing activities on white-capped albatross ecology.

Unfortunately, our fishing effort data set lacked information on locations or times of waste discharge by fishing vessels, which is known to attract seabirds, including white-capped albatrosses (BirdLife International 2008). Without data on these discharge events we are unable to assess the influence of fishery waste on white-capped albatross attendance during any trawl phase. Efforts are underway in New Zealand to examine the influence of various trawler waste discharge strategies on seabird attendance (Abraham et al. 2009, Bull 2009).

Previous studies have investigated overlap between seabirds and fishing activities, yet these studies have been at large spatial and temporal scales that generate significant gaps between bird and boat distributions. Our results demonstrate the benefits of deploying high-resolution GPS tags to quantify variability in overlap and interaction rates, and to better understand the ecological impacts of fishing activities on a seabird population. Studies of seabird bycatch based solely on observer data (Weimerskirch et al. 2000, Gandini \& Frere 2006, Sullivan et al. 2006) have limited application to assessments of overall population risk and ecological impact because only birds that interact with vessels or gear are quantified; no account is made for birds that do not associate with fishing activities. Satellite and geolocator telemetry devices have been used previously to assess seabird overlap with fishing activity, but only at an aggregated spatial scale of $5^{\circ}$ grid squares (e.g. BirdLife International 2004, Phillips et al. 2006). One previous study used GPS tags to examine albatross and fisheries associations, but only to scales of 1' (Waugh et al. 2005). Votier et al. (2010) modeled the responses of northern gannets Morus bassanus to fishing vessel locations derived from VMS data but only at scales of $5 \mathrm{~km}$ and $2 \mathrm{~h}$ or aggregated annual VMS data. Our study provides a stepwise improvement on the scale of resolution for studying seabirdfishery associations by identifying precise locations of overlap between individual seabirds and individual fishing boats, allowing improved estimates of overlap rates. These unique results are attributable to both the novel data sets available to us and our novel methods enabling a fine-scale level of analysis.

However, this scale of analysis can still be improved with increased resolution of fishing effort data sets. Owing to the scales at which the fishing effort data were recorded, our efforts to quantify association rates between fine-scale white-capped albatross tracks and fishing activity were constrained. Linking 3 data sets (GPS tracks, VMS data, and catch effort data) with diverse levels of spatial and temporal resolutions, in both time and space, proved to be a complex task. While our attempt to compensate for such resolution discrepancies between albatross GPS points and fishing vessel tracks (VMS data set) may be imperfect, our results represent a first effort to quantify overlap rates between individual birds and boats. Although no definitive overlap rate is known, we acknowledge that our estimates may be imperfect owing to (1) points mislabeled overlap because of large spatial buffers (>7 km), (2) points mislabeled non-overlapping owing to the small temporal window applied in the overlap analysis (3 $\mathrm{min})$ and (3) points mislabeled non-overlapping because of overlap events that occurred outside the spatial buffers created based on theoretical vessel movements. Although highly informative, our results emphasize the need for more precise data collection of fishing activities in order to identify precise association events between birds and boats. Otherwise, substantial spatio-temporal lags can occur between GPS data collected at fine spatial and temporal scales and fishing data collected at lower scales.

We acknowledge that the fisheries data used in this study are among the highest quality data sets available 
worldwide and were not collected for comparison with seabird tracking data. However, this is an important and useful application of these fishing data that could generate effective conservation management. We advocate the increased availability of VMS and catch effort data sets to scientists worldwide for comparison with the distribution of threatened marine fauna. Additionally, although high-resolution GPS tags are a superb tool to record individual movement patterns, critical conservation issues related to habitat protection and bycatch reduction cannot be addressed with GPS technology alone. Scale discrepancies between GPS track data sets and fishing effort and environmental data sets limit our ability to fully understand finescale marine megafauna behavior and ecology. To effectively manage fisheries interactions with threatened marine animals, environmental and fishing effort data sets of higher spatial and temporal resolution, equivalent to GPS tracking data, are necessary. Conservation advocates may need to apply coordinated pressure on governmental agencies to produce these data sets and make them available to scientists.

Understanding and quantifying the ecological impact to animals by a spatially and temporally distributed anthropogenic threat, such as commercial fisheries, is difficult yet essential for effective conservation. In our study we incorporated fine-scale tracking data and fine-scale fishing effort data to demonstrate that white-capped albatrosses change their foraging behavior when overlapping a fishing vessel. Additionally, our analyses determined a relatively high rate of overlap (68\%) between albatrosses and fishing vessels, with a strong concentration of overlap in the Auckland Island shelf region. Our study represents a first effort to combine high-resolution GPS tracking data with detailed fishing effort data to quantify rates of overlap between individual birds and individual fishing vessels to better understand the effects of fishing activities on seabirds. To determine the full effects of fishing activities on seabird populations, including the white-capped albatross, we need long-term demographic data of seabird populations and increased sample sizes of fine-scale interactions between individual birds and fishing vessels or gear, including precise locations, times and outcomes of these events. Colaborative efforts between scientists, government agencies, fisheries and fishery managers can yield these data to provide realistic assessments of seabird response to fishing activities so that appropriate conservation measures can be applied.

Acknowledgements. Funding for this study was provided by the Conservation Services Programme of the New Zealand Department of Conservation (Project POP2005/02). We are grateful to The New Zealand Ministry of Fisheries for supply- ing fishing vessel and catch effort data. We thank M. Williams (NIWA, Wellington) for assistance with Matlab, P. Jameson and N. Gemmell for laboratory facilities at the University of Canterbury, and the crew of RV 'Tiama' for safely transporting our field crew to the sub-Antarctic and back again.

\section{LITERATURE CITED}

Abraham ER, Pierre JP, Middleton DAJ, Cleal J, Walker NA, Waugh SM (2009) Effectiveness of fish waste management strategies in reducing seabird attendance at a trawl vessel. Fish Res 95:210-219

Baird SJ (2008) Net captures of seabirds during trawl fishing operations in New Zealand waters. National Institute of Water and Atmospheric Research, Wellington

Baker GB, Double MC, Gales R, Tuck GN and others (2007) A global assessment of the impact of fisheries-related mortality on shy and white-capped albatrosses: conservation implications. Biol Conserv 137:319-333

Barraquand F, Benhamou S (2008) Animal movements in heterogeneous landscapes: identifying profitable places and homogeneous movement bouts. Ecology 89: 3336-3348

> Bartle JA (1991) Incidental capture of seabirds in the New Zealand subantarctic squid trawl fishery, 1990. Bird Conserv Int 1:351-359

Benhamou S, Bovet P (1989) How animals use their environment: a new look at kinesis. Anim Behav 38:375-383

BirdLife International (2004) Tracking ocean wanderers: the global distribution of albatrosses and petrels. Results from the Global Procellariform Tracking Workshop, Gordon's Bay, South Africa, 1-5 Sep 2003. BirdLife International, Cambridge

BirdLife International (2008) Species factsheet: Thalassarche steadi. BirdLife International, Cambridge

Bull LS (2009) New mitigation measures reducing seabird bycatch in trawl fisheries. Fish Fish 10:408-427

Cherel Y, Klages NTW (1998) A review of the food of albatrosses. In: Robertson G, Gales R (eds) Albatross biology and conservation. Surrey Beatty \& Sons, Chipping Norton, p 113-136

Conservation Services Programme (2008) Summary of autopsy reports for seabirds killed and returned from observed New Zealand fisheries: 1 October 1996-30 September 2005, with specific reference to 2002/03, 2003/04, 2004/05. Department of Conservation, Wellington

- Croxall JP, Prince PA (1994) Dead or alive, night or day: How do albatrosses catch squid? Antarct Sci 6:155-162

> Fauchald P, Tveraa T (2003) Using first-passage time in the analysis of area-restricted search and habitat selection. Ecology 84:282-288

Fridolfsson AK, Ellegren H (1999) A simple and universal method for molecular sexing of non-ratite birds. J Avian Biol 30:116-121

Gales R (1998) Albatross populations: status and trends. In: Robertson G, Gales R (eds) Albatross biology and conservation. Surrey Beatty \& Sons, Chipping Norton, p 20-45

Gandini P, Frere E (2006) Spatial and temporal patterns in the bycatch of seabirds in the Argentinian longline fishery. Fish Bull 104:482-485

Griffiths R, Double MC, Orr K, Dawson RJB (1998) A DNA test to sex most birds. Mol Ecol 7:1071-1075

Heithaus MR, Frid A, Wirsing AJ, Worm B (2008) Predicting ecological consequences of marine predator declines. Trends Ecol Evol 23:202-210

Lewison RL, Crowder LB (2003) Estimating fishery bycatch 
and effects on a vulnerable seabird population. Ecol Appl 13:743-753

Lewison RL, Crowder LB, Read AJ, Freeman SA (2004) Understanding impacts of fisheries bycatch on marine megafauna. Trends Ecol Evol 19:598-604

Ministry of Fisheries (2006) Catch effort reference library. New Zealand Ministry of Fisheries, Wellington

Nevitt GA (2008) Sensory ecology on the high seas: the odor world of the procellariform seabirds. J Exp Biol 211: 1706-1713

Phillips RA, Silk JRD, Croxall JP, Afanasyev V (2006) Yearround distribution of white-chinned petrels from South Georgia: relationships with oceanography and fisheries. Biol Conserv 129:336-347

Prince PA, Croxall JP, Trathan PA, Wood AG (1998) Pelagic distribution of South Georgia albatrosses and their relationship with fisheries. In: Robertson G, Gales R (eds) Albatross biology and conservation. Surrey Beatty \& Sons, Chipping Norton, p 137-167

Robertson BC, Gemmell NJ (2006) PCR-based sexing in conservation biology: wrong answers from an accurate methodology? Conserv Genet 7:267-271

Robertson CJR, Bell E, Scofield P (2004) Autopsy report for seabirds killed and returned from New Zealand fisheries, 1 October 2001 to 30 September 2002. New Zealand Department of Conservation, Wellington

Rodgers AR, Carr AP, Beyer HL, Smith L, Kie JG (2007) HRT: home range tools for ArcGIS. Version 1.1. Ontario Ministry of Natural Resources, Centre for Northern Forest Ecosystem Research, Thunder Bay
Sullivan BJ, Reid TA, Bugoni L (2006) Seabird mortality on factory trawlers in the Falkland Islands and beyond. Biol Conserv 131:495-504

Sutherland WJ (1996) From individual behaviour to population biology. Oxford University Press, Oxford

Thompson DR (2009) Autopsy report for seabirds killed and returned from observed New Zealand fisheries: 1 October 2005 to 30 September 2006. New Zealand Department of Conservation, Wellington

Votier SC, Bearhop S, Witt MJ, Inger R, Thompson DR, Newton J (2010) Individual responses of seabirds to commercial fisheries revealed using GPS tracking, stable isotopes and vessel monitoring systems. J Appl Ecol 47: $487-497$

Waugh S, Filippi D, Fukuda A, Suzuki M, Higuchi H, Setiawan A, Davis L (2005) Foraging of royal albatrosses, Diomedea epomophora, from the Otago Peninsula and its relationships to fisheries. Can J Fish Aquat Sci 62: 1410-1421

> Weimerskirch H, Capdeville D, Duhamel G (2000) Factors affecting the number and mortality of seabirds attending trawlers and long-liners in the Kerguelen area. Polar Biol 23:236-249

Weimerskirch H, Bonadonna F, Bailleul F, Mabille G, Dell'Omo G, Lipp HP (2002) GPS tracking of foraging albatrosses. Science 295:1259

> Weimerskirch H, Pinaud D, Pawlowski F, Bost CA (2007) Does prey capture induce area-restricted search? A fine-scale study using GPS in a marine predator, the wandering albatross. Am Nat 170:734-743

Appendix 1. Molecular sexing methods

To determine the gender of each tagged white-capped albatross Thalassarche steadi we obtained approximately $0.5 \mathrm{ml}$ of blood from the tarsal vein with a 25 gauge needle. Blood samples were stored in $70 \%$ ethanol in Eppendorf microcentrifuge vials. The sex of all samples was determined with 2 independent molecular tests of sex to reduce the potential for sexing errors (Robertson \& Gemmell 2006). Results from the 2 tests matched each other for all birds sampled in this study. Molecular sexing was done with PCR primers for the chromo-helicase-DNA-binding gene (primer pair P2 and P8, Griffiths et al. 1998; primer pair 2987 and 3112, Fridolfsson \& Ellegren 1999). PCR amplifications were done in $25 \mu l$ reaction volumes containing ca. $50 \mathrm{ng}$ of template DNA, $1.0 \mathrm{pmol}$ of each primer, $200 \mu \mathrm{M}$ each of dATP, dGTP, dTTP and dCTP, $50 \mathrm{mM} \mathrm{KCl}, 10 \mathrm{mM}$ Tris$\mathrm{HCl}_{1} \mathrm{pH} 9.0,1.5 \mathrm{mM} \mathrm{MgCl}_{2}$ and 0.5 unit of Taq polymerase (Bioline USA). The thermal cycling parameters were an initial 2 min denaturation at $94^{\circ} \mathrm{C}$, followed by 30 cycles at $94^{\circ} \mathrm{C}$ for $15 \mathrm{~s}, 48^{\circ} \mathrm{C}$ for $25 \mathrm{~s}$ and $72^{\circ} \mathrm{C}$ for $45 \mathrm{~s}$. PCR products for primer pair 2987 and 3112 were resolved on a $2 \%$ agarose gel (Tris-borate-EDTA [TBE]: $134 \mathrm{mM}$ Tris, $74.9 \mathrm{mM}$ boric acid, $2.55 \mathrm{mM}$ EDTA, pH 8.8) or, for primer pair P2 and P8, by means of HaeIII digestion (Griffiths et al. 1998) and a $3 \%$ agarose gel. 
Appendix 2. Full description of methods to identify overlap between albatross GPS points and fishing vessel tracks from vessel monitoring system (VMS) data

Code was written with Matlab (v. 7.6, R2008a, The MathWorks) to iteratively perform the following steps to determine overlap between each albatross track point and all fishing vessel tracks (see Fig. 2 for illustration of methods).

For every pair of consecutive VMS points, $\mathrm{VMS}_{1}$ and $\mathrm{VMS}_{2}$ :

(1) Calculate the time length between VMS points: $T=$ time $_{2}-$ time $_{1}$.

(2) Determine the number of points to be generated in between VMS points: $\mathrm{n}=T / 3$ min intervals.

(3) Calculate the distance $(R)$ between $\mathrm{VMS}_{1}$ and $\mathrm{VMS}_{2}$.

(4) Calculate average vessel speed between $\mathrm{VMS}_{1}$ and $\mathrm{VMS}_{2}$ based on speed stamps at the 2 VMS points: $S=\left(\right.$ speed $_{1}+$ $\left.\operatorname{speed}_{2}\right) / 2$.

(5) Determine the length of each segment in between each 3 min point: $\mathrm{d} R=R / \mathrm{n}$.

(6) Calculate the maximum potential distance ( $\mathrm{pD}$ ) the vessel could have travelled: $\mathrm{pD}=S \times T$.

(7) Calculate the excess distance $(\mathrm{eD})$ that the vessel did not travel owing to turning or slowing, for example: $\mathrm{eD}=\mathrm{pD}-R$.

(8) Determine the midpoint (MP) between the 2 consecutive VMS points $\left(\mathrm{VMS}_{1}\right.$ and $\left.\mathrm{VMS}_{2}\right)$. This is the point that will have the largest spatial buffer because it has the maximum uncertainty of the vessel's location. $\mathrm{MP}=\mathrm{n} / 2$, rounded down to the nearest integer.

(9) Determine the radius (a) of the spatial buffer at MP using the Pythagorean theorem, where $c=\mathrm{eD} / 2, b=\mathrm{MP} \times \mathrm{dR}$, $a=\sqrt{\left(c^{2}-b^{2}\right)}$

(10) Calculate $\left(\mathrm{n}_{\mathrm{i}}\right)$ based on $a$, the buffer radius $\left(r^{\mathrm{i}}\right)$ for each 3 min point:

Buffer radius for point $\mathrm{n}_{\mathrm{i}}=\left[a \times\left(\mathrm{n}_{\mathrm{i}} / \mathrm{MP}\right)\right]$.

For $\mathrm{n}_{0}$ (same as $\mathrm{VMS}_{1}$ and $\mathrm{VMS}_{2}$ ): Buffer radius $=\mathrm{dR}$. Small radius buffers were applied to these points (actual VMS positions) because an albatross is unlikely to have the exact same position as a vessel's VMS transponder, but rather be within a few hundred meters. If there was an even number of generated 3 min points (n), then the last point before $\mathrm{VMS}_{2}$ has a buffer radius $=\mathrm{dR}$.

(11) Calculate the limit distance (ID) if $\mathrm{pD}<R$ for any vessel track (the average speed was slower than the actual speed needed to get from $\mathrm{n}_{1}$ to $\mathrm{n}_{2}$ ): $\mathrm{ID}=R-\mathrm{pD}$. One-half of the $\mathrm{ID}$ was then used as the buffer radius for all 3 min points along these tracks. This scenario was infrequent.

(12) Evaluate all points along each albatross track to identify those points that fell within the created spatial radius buffers and within a \pm 3 min temporal window of the VMS point or generated 3 min interval along the vessel tracks.

Editorial responsibility: Rory Wilson, Swansea, UK
Submitted: October 5, 2010; Accepted: January 31, 2011

Proofs received from author(s): April 8, 2011 